\title{
Travelling bioethics
}

\author{
Henk ten Have $\cdot$ Bert Gordijn
}

Published online: 18 November 2010

(C) The Author(s) 2010. This article is published with open access at Springerlink.com

When there are no strikes or natural disasters, travelling usually is a pleasure. Some of us have returned from the annual conference of the American Society for Bioethics and Humanities in San Diego, while others have good memories of the 10th World Congress of Bioethics in Singapore last summer. But not only bioethicists are travelling, bioethics itself is as well, following the globalization of health care and medical research. Anthropologist Petryna (2009), in her interesting book When experiments travel, has shown how the clinical trials industry has moved into the developing countries, using the poor as research subjects and ignoring all the norms that have been established in the developed world.

Bioethics has become a global concern and has now really moved into a new stage involving all countries and cultures. This issue of the journal testifies of this expansion of the scope of bioethics.

However, there are different perspectives on the globalization of bioethics. In this issue, Gielen et al. (2011) report about the attitudes of palliative care professionals in New Delhi towards withholding life-sustaining treatment. The need for palliative care exists everywhere. It is therefore interesting to study how non-treatment decisions are made in other countries. The authors refer to the specific context in India, such as the legal provisions that facilitate that refusal of life-sustaining treatment can be regarded as suicide, making physicians reluctant to withdraw or withhold such treatment. The authors also, though succinctly, refer to the socio-economic context, pointing out that financial considerations play an important role in treatment

H. ten Have $(\bowtie) \cdot$ B. Gordijn

Dublin City University, Dublin, Ireland

e-mail: tenhaveh@duq.edu decisions. Regardless of these different contexts, however, the respondents use more or less the same normative framework for decisions to withhold life-sustaining treatment as in the West. It is difficult to know how representative the opinions of less than 30 physicians and nurses in various palliative care settings in New Delhi are for palliative care professionals in India. After all, the respondents are highly educated people, imbued with the attitudes of palliative care and not much influenced by Hindu beliefs.

But the study demonstrates that there are two different research approaches to global bioethical issues. One approach is to study other countries to examine how ethical problems are perceived, presented, addressed, for example to examine how treatment decisions in palliative care are made in India or other countries. We can apply the usual research methods with the standard questionnaire and hypothetical cases to gauge the opinions of colleagues in India. The results often trigger a response similar to the exclamation of surprise of Western tourists in Bangkok or Nairobi: 'it is just like home'- 'they have everything we have'. Modern health care is universal, medicine is almost the same everywhere, and people have similar diseases. Why should bioethics be different? Everybody who leaves the main roads and looks beyond the glamorous buildings finds a different reality. Nairobi has one of the vastest slumps in Africa, while Bangkok has huge areas of cardboard huts 'sheltering' illegal laborers from the Northern provinces. Palliative care in India is fine, but can we ignore the context? India is a vast country, with $25 \%$ of the population below the poverty line. The majority of the population has no access to health care; only $10 \%$ of the population has health insurance. There is a shortage of doctors and nurses, and a significant lack of hospital beds. Even if there are adequate health facilities, basic sanitation is lacking. There is no city at the moment with full-day water supply. Within this context, 
ethical problems in palliative care seem insignificant. This does not mean that studying them is irrelevant, but it is like staying in the Hilton Hotel in downtown Nairobi: comfortable but isolated.

The other approach is to study what specific problems health professionals actually are facing in a vast and diverse country like India. An example is provided in an earlier publication in this journal (Chattopadhyay and Simon 2008). The authors of this study explicitly attend to the context in which individuals understand the meaning of illness, suffering and death. How physicians, patients and family communicate is profoundly influenced by culture, particularly in regard to end-of-life decisions. Their findings are different from Gielen et al. When illness is a shared family affair, the diagnosis of a fatal disease is often not communicated to the patient; advanced directives are virtually non-existent; the family makes all decisions. The implication is that the usual normative framework can no longer be applied, and needs to be reformulated from within the perspective of the country and the culture.

Similar challenges were faced in a research project described in another publication in this issue, from the same research group in Louvain (Van den Branden and Broeckaert 2011). The researchers studied English online fatwas in the field of end-of-life ethics. The rapidly increasing number of e-fatwas in itself is a symptom of globalization of a traditional religion and is apparently related to the struggle for normative authority in presentday Islamic bioethics. But the new media will not necessarily convey a new message. Basically using the same conceptual framework on treatment decisions in advanced disease as in India, this time the researchers were surprised to find out that the fatwas did not follow the framework. Islamic arguments do not make a difference between voluntary euthanasia, non-voluntary euthanasia and assisted suicide. Of course, it would have been an even bigger surprise, if fatwas of an ancient religion would have been promulgated according to the conceptual structure recently invented by theologians in Louvain. Studying Islamic bioethics requires immersion in the Islamic world view and reasoning. Even the suggestion that the practice might be different, and that perhaps the actual and concrete decisionmaking process might be following the researchers' framework, presupposes the typically western distinction between normative ideas and normative practice.

Taking seriously the bioethical questions and answers in different countries, cultures and religions implies not to impose a particular normative framework but to do as much justice as possible to the normative considerations and concerns existing in these different contexts. This is why the above studies are important. We need to know in detail and with precision what are the ethical problems in other communities and regions, what are the strategies of argumentation and justification used, and what are the approaches and solutions to address these problems. But bioethics is not anthropology. This phase of exploration and clarification should just be the starting-point for what seems to be essential in genuine bioethics: normative analysis. However, often the research never reaches this point; it is jammed in the empirical domain. It provides excellent descriptions but no normative judgment. What seems to be presented as bioethics is in reality anthropology. An example is the above mentioned book by Petryna. She provides an excellent narrative of internationalization of clinical trials but she does not make a critical judgment. In fact her book is a long history of exploitation, social injustice and manipulation of regulations.

Another problem surfaces when normative judgments are indeed made on the basis of empirical research: ethical relativism and particularism. What is considered as right or wrong in the healthcare setting depends on the sociocultural context. Ethical conclusions are drawn on the basis of the anthropological approach but they are always situated within the specific culture. An example offer Chattopadhyay and De Vries (2008). They argue that modern bioethics is a typical Western phenomenon. It is born in the West and therefore will always have the birthmarks of Western civilization. When it is globalised, it will have become the agent of moral imperialism. This argument seems to demonstrate modesty and respect for cultural diversity. Who are we to impose our judgment on another culture? Nobody wants to be considered a bioethical imperialist. But in real practice this argument might also be fallacious and even unjust. It is a fallacy because the genesis of an activity is not identical to its validity. Our number system is inherited from the Arab culture. We are not accusing the Arabs of colonialism since they have imposed their number system on us. It would be difficult to do that anyway since the Arabic numerals have been inherited from the Hindus in India. The argument is also unjust. It is 'doublespeak' to justify conditions and circumstances that are reproachable from the point of view of universal values. 'Asian values' for example have often been promoted to justify authoritarian regimes. But, as Sen (1997) has shown, the so-called Asian values are not especially Asian in any significant sense. It is a kind of 'moral protectionism' to continue to regard basic ethical notions and human rights as "Western values" that cannot be exported to other cultures. It is useful to quote Sen's conclusion: "Our ideas of political and personal rights have taken their particular form relatively recently, and it is hard to see them as "traditional" commitments of Western cultures. There are important antecedents of those commitments, but those antecedents can be found plentifully in Asian cultures as well as Western cultures" (1997, p. 38). 
Open Access This article is distributed under the terms of the Creative Commons Attribution Noncommercial License which permits any noncommercial use, distribution, and reproduction in any medium, provided the original author(s) and source are credited.

\section{References}

Chattopadhyay, S., and R. De Vries. 2008. Bioethical concerns are global, bioethics is Western. Eubios Journal of Asian and International Bioethics 18(4): 106-109.

Chattopadhyay, S., and A. Simon. 2008. East meets west: Crosscultural perspective in end-of-life decision making from Indian and German viewpoints. Medicine, Health Care and Philosophy 11(2): 165-174.

Gielen, J., Bhatnagar, S., Mishra, S., Chaturvedi, A.K., Gupta, H., Rajvanski, A., Van den Branden, S., and B. Broeckaert. 2011.
Can curative or life-sustaining treatment be withheld or withdrawn? The opinions and views of Indian palliative-care nurses and physicians. Medicine, Health Care, and Philosophy $14(1)$, this issue.

Petryna, A. 2009. When experiments travel. Clinical trials and the global search for human subjects. Princeton and Oxford: Princeton University Press.

Sen, A. 1997. Human rights and Asian values: what Kee Kuan Yew and Le Peng don't understand about Asia. The New Republic July 14: 217(2-3): 33-38. http://www.hmb.utoronto.ca/HMB 303H/weekly_supp/week-02/Sen_Asian_Values.pdf.

Van den Branden, S., and B. Broeckaert. 2011. Living in the hands of God. English Sunni e-fatwas on (non-)voluntary euthanasia and assisted suicide. Medicine, Health Care, and Philosophy 14(1), this issue. 